Jurnal Mahasiswa BK An-Nur : Berbeda, Bermakna, Mulia

Volume 4 Nomor 1 Tahun 2018

Tersedia Online: https://ojs.uniska-bjm.ac.id/index.php/AN-NUR

ISSN. 2460-9722

\title{
LAYANAN KONSELING KELOMPOK DENGAN TEKNIK SELF MANAGEMENT UNTUK MENGURANGI PERILAKU SISWA MEMBOLOS DI SMPN 29 BANJARMASIN TAHUN AJARAN 2017/2018
}

\author{
Amaliyah, Hamzah, Farial \\ Universitas Islam Kalimantan Muhammad Arsyad Al-Banjari \\ amaliyah21@yahoo.com
}

\begin{abstract}
ABSTRAK
Latar belakang yang terjadi bahwa adanya siswa kelas IX SMPN 29 Banjarmasin yang suka membolos. Dengan layanan konseling kelompok dengan teknik self management diharapkan perilaku siswa membolos dapat dikurangi. Tujuan utama dalam penelitian ini adalah untuk mengetahui apakah layanan konseling kelompok dengan teknik self management dapat mengurangi perilaku siswa membolos. Jenis penelitian yang digunakan dalam penelitian ini adalah Penelitian Tindakan Bimbingan dan Konseling (PTBK) yang dilaksanakan dengan 2 siklus. Subyek penelitian ini yaitu lima orang siswa kelas IX SMPN 29 Banjarmasin yang teridentifikasi pernah membolos. Metode yang digunakan dalam penelitian ini adalah analisis deskriftif kualitatif. Setelah mengikuti layanan konseling kelompok dengan teknik self management siklus 1 dengan dua kali pertemuan terdapat satu orang siswa yang tidak membolos lagi siswa tersebut adalah MAr, sedangkan empat orang siswa lainnya mengalami penurunan dalam perilaku membolos yaitu PAS menjadi dua kali, MIAF menjadi satu kali, MAk menjadi dua kali, dan SN menjadi dua kali. Dan setelah siswa mengikuti layanan konseling kelompok dengan teknik self managemen siklus 2 dengan satu kali pertemuan terdapat dua orang siswa yang tidak pernah membolos lagi siswa tersebut adalah PAS, dan MIAF sedangkan dua orang siswa lainnya masih membolos satu kali siswa tersebut adalah MAk dan SN. Kesimpulan dari penelitian ini adalah bahwa layanan konseling kelompok dengan teknik self management dapat mengurangi perilaku siswa membolos di SMPN 29 Banjamasin. Saran yang dapat direkomendasikan peneliti kepada konselor sekolah adalah agar konselor sekolah dapat memberikan layanan yang ada di Bimbingan dan konseling kepada siswa SMPN 29 Banjarmasin.
\end{abstract}

Kata Kunci : Konseling Kelompok, Perilaku Membolos, Self Management.

\begin{abstract}
Background that happened that the existence of students of class IX SMPN 29 Banjarmasin who like skipping. With group counseling services with self management techniques expected to trespass students can be reduced. The main purpose of this study was to find out whether group counseling services with self-management techniques can reduce the behavior of truant students. The type of research used in this study is Research Guidance and Counseling (PTBK) which is implemented with 2 cycles. The subjects of this study were five students of class IX SMPN 29 Banjarmasin who have been identified truant. The method used in this research is qualitative descriptive analysis. After attending a group counseling service with self management cycle 1 with two meetings there is one student who does not ditch again the student is MAr, while four other students have decreased in skipping behavior ie PAS twice, MIAF become one time, MAk become twice, and SN becomes twice. And after students follow group counseling service with self managment technique cycle 2 with one meeting there are two students who never ditch again the student is PAS, and MIAF while two other students still ditch one time the student is MAk and SN. The conclusion of this research is that group counseling service with self management technique can reduce the behavior of truant student in SMPN 29 Banjamasin. Suggestions that researchers can recommend to school counselors are so that school counselors can provide services that exist in Guidance and counseling to students SMPN 29 Banjarmasin.
\end{abstract}

Keywords: Group Counseling, Skipping Behavior, Self Management.

Dipublikasikan Oleh:

UPT Publikasi dan Pengelolaan Jurnal

Universitas Islam Kalimantan Muhammad Asyad Al-Banjarmasin 


\section{PENDAHULUAN}

Pendidikan mempunyai peran yang sangat strategis dalam meningkatkan kualitas sumber daya manusia dan mewujudkan cita-cita bangsa Indonesia dalam mewujudkan kesejahteraan umum dan mencerdaskan kehidupan bangsa. Pemerintah merumuskan dalam undang-undang Republik Indonesia Nomor 20 tahun 2003 tentang sistem Pendidikan Nasional yang menjelaskan bahwa pendidikan dilakukan agar mendapatkan tujuan yang diharapkan bersama yaitu "Pendidikan adalah usaha sadar dan terencana untuk mewujudkan suasana belajar dan pembelajaran agar peserta didik secara aktif mengembangkan potensi dirinya untuk memiliki kekuatan spiritual keagamaan, pengendalian diri, kepribadian, kecerdasan, akhlak mulia serta keterampilan yang diperlukan dirinya, masyarakaat, bangsa dan Negara" ( pasal 1 ayat 1 UU RI Nomor 20 Sistem Pendidikan Nasional. 2003).

Sekolah merupakan bagian dari pendidikan. Di sekolah inilah kegiatan belajar mengajar berlangsung. Komponen inti dalam kegiatan belajar mengajar adalah guru dan peserta didik. Ilmu pengetahuan diajarkankan dan dikembangkan kepada peserta didik. Segala sesuatu yang telah diprogramkan akan dilaksanakan dalam kegiatan belajar mengajar. Proses belajar mengajar dapat terlaksana apabila guru dan peserta didik hadir, jika salah satu komponen tersebut tidak hadir maka proses belajar mengajar tersebut tidak akan terlaksana.

Dari pandangan tersebut dapat diketahui bahwa kehadiran kompenen inti dalam kegiatan belajar mengajar sangatlah penting. Namun, melihat fenomena dilapangan saat ini menunjukan hal yang berbeda. Salah satu komponen inti dalam kegiatan belajar mengajar yaitu, peserta didik tidak hadir dengan alasan yang tidak bisa dipertanggungjawabkan atau yang lebih sering di sebut dengan membolos. Saat ini sering sekali ditemukan siswa yang membolos saat kegiatan belajar dan mengajar sedang berlangsung di sekolah.

Kejenuhan dan keengganan dalam menghadapi guru killer saat sedang menngikuti proses belajar mengajar tak jarang menjadi alasan siswa dalam membolos. Siswa terlihat bermain di tempat sekitar sekolah seperti kantin, dan di tempat luar sekolah seperti rental play station atau mall. Handoko (20113:2). Menurut Susanta (20014:11) Membolos adalah salah satu jenis kenakalan yang marak dilakukan oleh pelajar. Menurut Wikipedia, Truancy is unapproved absence from school, usually without aparent's knowledge. Dengan demikian setiap ketidakhadiran siswa tanpa alasan yang tepat atau alasan yang tidak diterima sekolah dapat disebut membolos, baik ketidakhadiran dalam beberapa jam
ISSN. 2460-9722

pelajaran maupun ketidakhadiran selama sehari penuh.

Berdasarkan studi pendahuluan yang peneliti lakukan pada hari Jumat tanggal 24 Maret 2017 di SMPN 29 Banjarmasin, peneliti mewawancarai guru BK dan dari hasil wawancara tersebut diketahui bahwa terdapat lima orang siswa kelas IX yang membolos, siswa tersebut adalah PAS, MIAF, MAk, MAr, dan SN baik yang membolos karena tidak masuk sekolah tanpa keterangan yang tidak dapat dipertanggungjawabkan maupun yang meninggalkan kelas di saat jam pelajaran tertentu. Membolos merupakan salah satu bentuk kenakalan siswa, yang jika tidak segera diatasi akan menimbulkan dampak yang lebih parah. Perilaku ini umumnya banyak di temui pada remaja mulai tingkat pendidikan Sekolah Menengah Pertama. Membolos tidak hanya menimbulkan kegagalan siswa dalam hal belajar seperti gagal ujian, dan tidak naik kelas, tetapi juga dapat membawa dampak yang lebih luas seperti terjerumus dalam dunia narkoba, seks bebas dan tawuran. Dalam hal ini peran seorang guru BK di sekolah diharapkan mampu untuk meminimalisir masalah yang di alami siswa, salah satu cara guru BK dalam meminimalisir masalah tersebut adalah dengan menggunakan layanan konseling kelompok.

Dalam bimbingan dan konseling, jenis layanan yang dapat digunakan untuk mengurangi perilaku membolos salah satunya ialah konseling kelompok, karena konselin kelompok memberikan kesempatan untuk mengekspresikan perasaan, konflik dan merealisasikan bahwa mereka senang berbagi perhatian dalam kelompok. Menurut Winkel \& Hastuti (2006:589) konseling kelompok merupakan bentuk khusus dari layanan konseling, yaitu wawancara konseling antara konselor professional dengan beberapa orang sekaligus yang tergabung dalam suatu kelompok kecil. Anitiara (2016:72) menyatakan perilaku membolos disekolah berkurang setelah diberikan layanan konseling kelompok. Hal ini ditunjukkan dengan adanya perubahan perilaku siswa pada setiap pertemuan konseling kelompok yang telah mengarah pada berkurangnya perilaku membolos siswa disekolah yang terlihat lebih baik dari sebelumnya.

Salah satu teknik yang dapat digunakan dalam konseling kelompok adalah teknik self management. Menurut Komalasari, Wahyuni, dan Karsih (2011:180) pengelolaan diri (self manajement) adalah prosedur dimana individu mengatur perilakunya sendiri. Melihat dari kegunaan serta tujuan konseling kelompok dan teknik self manajement tersebut, maka diharapkan dapat mengurangi perilaku membolos pada siswa di sekolah. 
Handoko (2013:130-131) menyatakan terdapat perubahan yang positif yaitu berupa penurunan yang signifikan pada perilaku membolos setelah diberi layanan konseling individual dengan pendekatan Behavior melalui teknik self management. Hal ini terbukti dari hasil uji wilxocon didapatkan $\mathrm{Z}$ hitung sebesar 2.20 dibandingkan dengan $\mathrm{Z}$ tabel dengan taraf signifikansi $0,025 \%$ dengan nilai $\mathrm{Z}$ tabel sebesar 1.96. Jadi hipotesis penelitian ini diterima. Maka dengan demikian layanan konseling individual dengan pendekatan behavioral melalui teknik self management dapat mengatasi perilaku membolos.

\section{METODE}

Metode yang digunakan dalam penelitian ini adalah Penelitian Tindakan Bimbingan dan Konseling (PTBK). Menurut Tadjri (2014:9) Penelitian Tindakan Bimbingan dan Konseling (PTBK) merupakan penelitian kolaboratif yang dilakukan konselor berdasarkan refleksi diri dengan tujuan untuk memperbaiki mutu layanan BK agar kesejahteraan siswa meningkat. Adapun populasi dalam penelitian ini adalah siswa SMPN 29 Banjarmasin kelas IX yang berjumlah 81 orang. Adapun sampel dalam penelitian ini adalah siswa SMPN 29 Banjarmasin yang berjumlah lima orang siswa dengan inisial PAS kelas IX-B, MIAF kelas IX-B, MAk kelas IX-C, MAr kelas IX-C dan SN kelas IX-C yang di identifikasi pernah membolos. Dalam teknik pengambilan sampel peneliti menggunakan teknik purpose sampling, menurut Sugiyono (2015:300) purposive sampling adalah teknik pengambilan sampel sumber data dengan pertimbangan tertentu. Pertimbangan tertentu ini, misalnya orang tersebut yang dianggap paling tau tentang apa yang kita harapkan, atau mungkin dia sebagai penguasa sehingga akan memudahkan peneiti menjelajahi obyek/situasi social yang diteliti. Dalam proses penelitian ini peneliti merencanakan dengan 2 siklus, dan siklus tersebut adalah sebagai berikut.

1. Rencana, menurut Tadjri (2014:51-57) langkahlangkah menyusun rencana tindakan meliputi :

a. Rumusan hipotesis

b. Menentukan jumlah siklus tindakan

c. Materi tindakan

Adapun perencanaan tindakan dalam penelitian yang akan peneliti laksanakan adalah:

a. Membuat rencana pelaksanaan layanan konseling kelompok dengan teknik self management yang meliputi waktu, tempat dan siswa yang dijadikan objek penelitian.

b. Menentukan jumlah siklus, yaitu dua siklus dengan satu siklus yang terdiri dari dua kali pertemuan.

c. Menyiapkan RPL beserta materi/topik bahasan dalam pelaksanaan layanan
ISSN. 2460-9722

konseling kelompok sesuai dengan aspek. (Terlampir, Lampiran 9)

d. Menyiapkan sumber, bahan dan alat bantu yang diperlukan.

2. Pelaksanaan, dalam pelaksaan Penelitian Tindakan yang akan peneliti lakukan adalah:

1) Tahap pembentukan kelompok;

a) Peneliti menyampaikan maksud dan tujuan dari konseling kelompok

b) Menjelaskan cara-cara dan asas-asas kegiatan konseling kelompok

c) Saling mengungkapkan dan mengenalkan diri

2) Tahap peralihan

a) Menjelaskan kegiatan yang akan di tempuh pada tahap berikutnya

b) Mengamati apakah para anggota kelompok apakah sudah siap menjalani kegiatan pada tahap berikutnya

c) Membahas suasana yang terjadi

d) Meningkatkan kemampuan keikutsertaan anggota

3) Tahap kegiatan

a) Masing-masing anggota bebas mengemukakan masalah

b) Menetapkan masalah yang akan di bahas terlebih dahulu

c) Anggota membahasa masalah secara mendalam

d) Penerapan teknik self managemen: (1) membantu siswa menentukan perilaku sasaran, (2) membantu siswa memonitor perilaku tersebut, (3) membantu siswa memilihih prosedur yang akan diterapkan, (4) mengarahkan siswa untuk melaksanakan prosedur tersebut, (5) mengevaluasi efektifitas prosedur tersebut.

4) Tahap penutup

a) Peneliti menyatakan bahwa kegiatan akan segera berakhir

b) Pemimpin dan anggota kelompok mengemukakan kesan dan hasil kegiatan

c) Membahas kegiatan lanjutan

d) Mengemukakan pesan dan harapan

\section{Pengamatan}

Menurut Tadjri (2014:40) pengamatan adalah teknik pengumpulan data dengan cara peneliti mengamati secara visual objek yang di amati. Tujuannya adalah untuk memperoleh data factual dan riil suatu objek sebagaindasar untuk menyusun deskripsi, seleksi dan analisis. Menurut Hidayat dan Bandrujaman (2012:61-62) pengamatan dapat di kelompokan menjadi dua yaitu pengamatan terhadap proses dan hasil, pengamatan terhadap proses pada 
umumnya meliputi pengamatan terhadap ketepatan prosedur pelaksanaan tindakan yang dilakukan guru $\mathrm{BK} /$ peneliti, data mengenai keaktifan siswa, serta tentang tanggapan/kepuasan siswa dalam mengikuti layanan.

Pengamatan dalam penelitian ini menggunakan skala penilaian. Menurut Anwar Sutoyo (2014:84) skala penilaian adalah pencatatn gejala menurut tingkattingkatannya. Bentuk pencatatn ini bukan hanya menggambarkan ada atu tidaknya gejala pada subjek yang sedang di amati seperti pada daftar ceklis, tetapi lebih dari itu berupaya menggambarkan kondisi subjek sesuai tingkatan-tingkatan gejalanya. Menurut Sutrisno Hadi (dalam Anwar Sutuyo, 2014:85) penggunaan rating scale ini sangat popular karena penggunaanya sangat mudah, di sisi lain pencatatannya lebih menunjukan keseragaman antara pencatat satu dengan lainnya, dan sangat sederhana untuk di analisis secara statistik. Adapun pedoman untuk pengamatan prosedur pelaksaan tindakan dan keaktifan siswa terlampir. Data hasil adalah data yang berkenaan dengan hasil/dampak dari tindakan yang di berikan. Pengamatan terhadap hasil dilakukan untuk melihat keberhasilan tinadakan variable masalah dalam PTBK. Data hasil itulah yang kemudian kita paparkan untuk menentukan apakah tindakan yang dilakukan berhasil atau tidak. Adapun pedoman pengamatan hasil terlampir (Lampiran 5). Di dalam pengamatan peneliti berkolaborasi dengan teman sejawat untuk mengamati pelaksanaan tindakan dan mengamati keaktifan siswa.

\section{Refleksi}

Menurut Tadjri (2014:45) data hasil pengamatan digunakan sebagai bahan refleksi diri dasar untuk melakukan PTBK. Refleksi adalah istilah yang mengandung arti memantulkan kembali/ mengungkapkan kembali/ merenungkan kembali/ menyatakan kembali. Hasil pengamatan yang terdokumentasi merupakan data pendukung yang sangat bermanfaat untuk refleksi diri. Pada tahap ini peneliti akan mengevaluasi proses pelaksanaan konseling kelompok dan mengevaluasi hasil frekuensi siswa membolos sebelum mengikuti konseling kelompok dengan teknik self managemen dan sesudah mengikuti konseling kelompok dengan teknik self managemen. Untuk mengetahui kebershasilan perbaikan di perlukan data yang dikumpulkan selama PTBK berlangsung. Dalam penelitian ini peneliti menggali data dengan menggunakan tiga cara yaitu observasi, wawancara, dan dokumentasi, yaitu :

\section{a. Observasi}

Menurut Anwar Sutuyo (2014:69-71) secara garis besar terdapat dua rumusan tentang pengertian observasi, yaitu pengertian secara sempit dan luas. Dalam arti sempit, observasi berarti pengamatan secara langsung terhadap gejala yang diteliti, dalam arti luas, observasi meliputi pengamatan yang dilakukan secara langsung maupun tidak langsung terhadap obyek yang sedang diteliti. Ada beberapa bentuk observasi yang lazim dilakukan oleh konselor dan atau peneliti, salah satunya yaitu observasi nonpartisipan. Observasi non-partisipan, yaitu bila observer tidak terlibat secara langsung atau tidak berpartisipasi dalam aktivitas yang sedang dilakukan observe. Dalam penelitian ini peneliti melakukan observasi non-partisipan, dan menggunakan beberapa alat bantu seperti skala penilaian untuk mengamati pelaksanaan tindakan, mengamati keaktifan siswa, dan mengamati hasil.

\section{b. Wawancara}

Menurut Tadjri (2014:65) Wawancara sebagai alat pengumpulan data adalah suatu cara pengumpulan data dengan mengadakan pembicaraan atau tanya jawab secara lisan antara orang yang mewawancarai dengan yang di wawancarai. Tujuan wawancara adalah untuk memperoleh data otentik dari sumber pertama yang berupa pernyataanpernyataan. Wawancara dalam penelitian ini berbentuk wawancara tak berstruktur. Menurut Sugiyono (2015:320) wawancara tidak terstruktur adalah wawancara yang bebas dimana peneliti tidak menggunakan pedoman wawancara yang telah tersusun secara sistematis dan lengkap untuk pengumpulan datanya. Pedoman wawancara yang digunakan hanya berupa garis-garis besar permasalahan yang akan di tanyakan.

Wawancara dilakukan kepada guru BK, guru mata pelajaran serta wali kelas IX-B dan IX-C SMP Negeri 29 Banjarmasin guna memperoleh data berupa frekuensi siswa membolos sebelum mengikuti konseling kelompok dengan tekniik self managemen dan frekuensi siswa setelah mengikuti konseling kelompok dengan teknik self managemen.

\section{c. Dokumentasi}

Menurut sugiyono (2015:329) dokumen adalah catatan peristiwa yang sudah berlalu. Dokumen bisa berbentuk tulisan, gambar, atau karya-karya monumental dari seseorang. Dokumentasi dalam penelitian ini perilaku siswa membolos dilihat dari buku catatan harian yang di kelola oleh guru BK SMPN 29 Banjarmasin.

PTBK adalah penelitian yang lebih banyak menggunakan pendekatan kualitatif. Salah satu bentuk analisis dalam pendekatan kualitatif adalah analisis deskriftif. Dalam penelitian ini peneiti menggunakan analisis deskriftif kualitatif. Menurut Tadjri (2014:7172) analisis deskriftif adalah analisis dengan menggambarkan data sebagaimana adanya, tidak menambah dan tidak pula megurangi.

\section{Dipublikasikan Oleh:}




\section{HASIL DAN PEMBAHASAN}

Untuk mengetahui kondisi awal perilaku siswa membolos di SMPN 29 Banjarmasin pneliti melakukan wawancara kepada guru BK sekaligus merangkap sebagai guru mata pelajaran di bidang Teknik Informasi Komputer (TIK) SMPN 29 Banjarmasin yang bernama Ibu Lili Ariani, S.Pd., wali kelas IX-B Ibu Hadijah, S.Pd., serta wali kelas IX-C Ibu Normilah, S.Ag.

Table 1 Kondisi Awal Perilaku Siswa Membolos Sebelum Mengikuti Layanan Konseling Kelompok dengan Teknik Self Management Siklus 1 dan siklus 2

\begin{tabular}{|c|c|c|l|}
\hline No. & Identitas & Kelas & $\begin{array}{l}\text { Jumlah } \\
\text { Membolos } \\
\text { (Kali) }\end{array}$ \\
\hline $\mathbf{1}$ & PAS & IX-B & 4 \\
\hline $\mathbf{2}$ & MIAF & IX-B & 3 \\
\hline $\mathbf{3}$ & MAk & IX-C & 6 \\
\hline $\mathbf{4}$ & MAr & IX-C & 2 \\
\hline $\mathbf{5}$ & SN & IX-C & 6 \\
\hline
\end{tabular}

Berdasarkan tabel di atas dapat di diketahui bahwa PAS sebelum mengikuti layanan konseling kelompok dengan teknik self management pernah membolos sebanyak empat kali, MIAF tiga kali, MAk enam kali, MAr dua kali, dan SN sebanyak enam kali.

Untuk pengamatan hasil setelah pelaksanaan siklus 1 dilihat dari catatan harian guru BK yang sekaligus merangkap sebagai guru mata pelajaran di SMPN 29 Banjarmasin pada hari Sabtu, 12 Agustus 2017 adapun hasil observasi tersebut sebagai berikut

Tabel 2 Hasil Pascatindakan Setelah Siswa Mengikuti Layanan Konseling Kelompok dengan Teknik Self Management Siklus 1

\begin{tabular}{|l|l|l|l|l|}
\hline No. & Identitas & Kelas & $\begin{array}{l}\text { Kondisi } \\
\text { Awal }\end{array}$ & $\begin{array}{l}\text { Siklus } \\
\mathbf{1}\end{array}$ \\
\hline $\mathbf{1}$ & PAS & IX-B & 4 & 2 \\
\hline $\mathbf{2}$ & MIAF & IX-B & 3 & 1 \\
\hline $\mathbf{3}$ & MAk & IX-C & 6 & 2 \\
\hline $\mathbf{4}$ & MAr & IX-C & 2 & 0 \\
\hline $\mathbf{5}$ & SN & IX-C & 6 & 2 \\
\hline
\end{tabular}

Berdasarkan table di atas dapat diketahui bahwa setelah mengikuti layanan konseling kelompok terdapat satu orang siswa yang tidak membolos lagi yaitu MAr sedangkan empat orang lainnya mengalami pengurangan, keempat siswa tersebut adalah PAS sebanyak dua kali, MIAF satu kali, MAk dua Kali, dan SN dua kali. Untuk mengetahui pengurangan

Dipublikasikan Oleh:

UPT Publikasi dan Pengelolaan Jurnal

Universitas Islam Kalimantan Muhammad Asyad Al-Banjarmasin
ISSN. 2460-9722

perilaku siswa membolos sebelum mengikuti layanan konseling kelompok dengan teknik self management dan setelah mengikuti layanan konseling kelompok dengan teknik self management siklus 1 lihat table berikut :

Tabel 3 Penguranagan Perilaku Siswa Membolos Sebelum dan Setelah Siswa Mengikuti Layanan Konseling Kelompok dengan Teknik Self Management Siklus 1

\begin{tabular}{|c|c|c|c|}
\hline No. & Identitas & Kelas & $\begin{array}{c}\text { Jumlah } \\
\text { Membolos } \\
\text { (Kali) }\end{array}$ \\
\hline $\mathbf{1}$ & PAS & IX-B & 2 \\
\hline $\mathbf{2}$ & MIAF & IX-B & 1 \\
\hline $\mathbf{3}$ & MAk & IX-C & 2 \\
\hline $\mathbf{4}$ & MAr & IX-C & 0 \\
\hline $\mathbf{5}$ & SN & IX-C & 2 \\
\hline
\end{tabular}

Dilihat dari table di atas setelah siswa mengikuti layanan konseling kelompok dengan teknik self management pada siklus 1 ada pengurangan perilaku membolos. Pengurangan perilaku siswa membolos masing-masing adalah PAS dua kali, MIAF dua kali, MAk empat kali, MAr dua kali dan SN empat kali.

Siklus 2

Berdasarkan hasil observasi pengamatan hasil akhir atau postest siklus 2 yang dilaksanakan pada hari Sabtu, 19 Agustus 2017 dilihat dari buku catatan harian guru BK SMPN 29 Banjarmasin diperoleh hasil sebagai berikut :

Table 4 Hasil Pascatindakan Setelah Siswa Mengikuti Layanan Konseling Kelompok dengan Teknik Self Management Siklus 1 dan Siklus 2

\begin{tabular}{|c|c|c|c|}
\hline No. & Identitas & Kelas & $\begin{array}{c}\text { Jumlah } \\
\text { Membolos }\end{array}$ \\
\hline & & & (Kali) \\
\hline & & & \\
\hline $\mathbf{1}$ & PAS & IX-B & 0 \\
\hline $\mathbf{2}$ & MIAF & IX-B & 0 \\
\hline $\mathbf{3}$ & MAk & IX-C & 1 \\
\hline $\mathbf{5}$ & MAr & IX-C & 0 \\
\hline
\end{tabular}


Table 5 Hasil Pengurangan Perilaku Siswa Membolos dari Kondisi Awal, Setelah Siklus 1 sampai Setelah Siklus 2 Mengikuti Layanan Konseling Kelompok dengan Teknik Self Management.

\begin{tabular}{|c|c|c|c|c|c|}
\hline No. & Iden & Kelas & $\begin{array}{c}\text { Kondisi } \\
\text { Awal }\end{array}$ & $\begin{array}{c}\text { Siklus } \\
\text { Siklus }\end{array}$ & $\mathbf{2}$ \\
\hline $\mathbf{1}$ & PAS & IX-B & 4 & 2 & 0 \\
\hline $\mathbf{2}$ & MIAF & IX-B & 3 & 1 & 0 \\
\hline $\mathbf{3}$ & MAk & IX-C & 6 & 2 & 1 \\
\hline $\mathbf{4}$ & MAr & IX-C & 2 & 0 & 0 \\
\hline $\mathbf{5}$ & SN & IXC & 6 & 2 & 1 \\
\hline
\end{tabular}

Berdasarkan table di atas dapat diketahui bahwa setelah mengikuti layanan konseling kelompok dengan teknik self management siswa mengalami pengurangan perilaku membolos terdapat tiga orang siswa tidak pernah membolos lagi siswa tersebut adalah PAS, MIAF, dan MAr sedangkan dua orang siswa lainnya masih membolos sebanyak satu kali, siswa tersebut adalah MAk dan SN.

Berdasarkan table di atas dapat diketahui bahwa telah terjadi pengurangan perilaku siswa membolos dari kondisi awal ke siklus 1 dan ke siklus 2. Sebelum siswa mengikuti layanan konseling kelompok dengan teknik self management siklus 1 dan 2 PAS pernah membolos sebanyak empat kali, MIAF tiga kali, MAk enam kali, MAr dua kali, dan SN enam kali. Setelah mengikuti kegiatan konseling kelompok dengan teknik self management siklus 1 salah satu siswa tidak pernah membolos lagi siswa tersebut adalah MAr, sedangkan empat orang lainnya masih membolos masing-masing siswa tersebut adalah PAS dua kali, MIAF satu kali, MAk dua kali, dan SN dua kali. Dan setelah mengikuti kegiatan konseling kelompok dengan teknik self management siklus 2, ada tiga orang siswa yang tidak pernah membolos lagi siswa tersebut adalah PAS, MIAF dan MAr. sedangkan dua orang lainnya masih membolos 1 kali siswa tersebut ialah MAk dan SN.

\section{PENUTUP}

Berdasarkan hasil penelitian yang telah dilakukan dan pembahasan hasil penelitian dengan judul mengurangi perilaku siswa membolos dengan teknik self management di SMPN 29 Banjarmasin, dapat di simpulkan sebagai berikut :

1. Kondisi awal sebelum siswa mengikuti layanan konseling kelompok dengan teknik self management siklus 1 dan 2 PAS pernah membolos
ISSN. 2460-9722

empat kali, MIAF tiga kali, MAk enam kali, MAr dua kali, san SN enam kali.

2. Setelah mengikuti layanan konseling kelompok dengan teknik self management siklus 1 dengan dua kali pertemuan ada satu siwa yang tidak membolos lagi siswa tersebut adalah MAr, sedangkan empat orang siswa lainnya mengalami penurunan dalam perilaku membolos yaitu PAS menjadi dua kali, MIAF menjadi satu kali, MAk menjadi dua kali, dan SN menjadi dua kali. Dan setelah siswa mengikuti layanan konseling kelompok dengan teknik self managemen siklus 2 dengan satu kali pertemuan terdapat dua orang siswa yang tidak pernah membolos lagi siswa tersebut adalah PAS, dan MIAF sedangkan dua orang siswa lainnya masih membolos satu kali, siswa tersebut adalah MAk dan SN.

3. Berdasarkan hasil penelitian dan pembahasan di bab sebelumnya dapat diketahui bahwa layanan konseling kelompok dengan teknik self management dapat mengurangi perilaku siswa membolos di SMPN 29 Banjamasin.

\section{REFERENSI}

Aisya, D. N. 2013. Jenis-jenis Layanan Bimbingan dan Konseling. Skripsi online dalam http://devinuraisya.blogspot.co.i d/, Di akses Tanggal 8 April 2017

Anitiara. 2016. Pengurangan Perilaku Membolos Di Sekolah Dengan Menggunakan Konseling Kelompok Pada Siswa Kelas Viii Smp Negeri 2 Kotabumi Tahun Ajaran 2015/2016. Skripsi

Online dalam http://digilib.unila.ac.id/23887/7/ SKRIPSI\%20TANPA\%20BAB

\%20PEMBAHASAN.pdf. Di akses Tanggal 8 April 2017

Azwar, S. 2016. Sikap Manusia Teori dan Pengukurannya. Yokgyakarta: Pustaka Belajar

Handoko, A. (2013). Mengatasi Perilaku Membolos Melalui Konseling Individual Menggunakan Pendekatan Behavior Dengan Teknik Self Management pada Siswa Kelas X TKJ SMK Bina Nusantara Ungaran Tahun Ajaran 2012/2013 (Doctoral dissertation, Universitas Negeri Semarang).

Hidayat, D.R dan Badrujaman, A. 2012. Penelitian Tindakan dalam Bimbingan dan Konseling. Jakarta Barat: Indeks

Ibrahim, A.S. 2015. Hubungan Antara Motivasi Belajar Dengan Perilaku Membolos Pada Siswa Kelas Viii Smp Batik Surakarta. Naskah Publikasi, 1(1). Di akses Tanggal 16 Juni 2017.

Indayani, A., Sedanayasa, G., Antari, N. N. M., \& Erg, M. (2014). Penerapan Konseling Behavioral Dengan Teknik Penguatan Positif Sebagai Upaya Untuk Meminimalisasi 
Perilaku Membolos Pada Siswa Kelas X. 1

ISSN. 2460-9722

Sma Negeri 1 Sawan Tahun Ajaran 2013/2014. Jurnal Ilmiah Bimbingan Konseling, 2(1). Di akses Tanggal 29 Maret 2017

Komalasari, G. Wahyuni, E. dan Karsih. 2011. Teori dan Teknik Konseling. Jakarta Barat: Indeks

Kurnanto, M.E. 2014. Konseling Kelompok. Bandung: Alfabet

Prayitno dan Amti. E. 2013. Dasar-Dasar Bimbingan dan Konseling. Jakarta: Rineka Cipta

Sugiyono. 2015. Metode Penelitian Pendidikan Pendekatan Kuantitatif, Kualitatif, dan $R \& D$. Bandung: Alfabeta

Tadjri, I. 2014. Penelitian Tindakan Bimbingan dan Konseling. Semarang: Swadaya Manunggal

Tutiona, M. Y., Munir, A., \& Ratu, B. (2016). Upaya mengurangi perilaku membolos melalui konseling individual dengan teknik behavior contract pada siswa SMP Negeri 6 Palu. Jurnal Konseling dan Psikoedukasi, 1(1). Di akses Tanggal 1 April 2017

Ummi. 2015. Meningkatkan Kepercayaan

Diri Siswa dalam Mengemukakan Pendapat

Melalui Layanan Informasi

Menggunakan Media Film Kelas X-3 di SMA Korpri Banjarmasin. SkripsiS1

Universitas Islam Kalimantan

Undang Undang Republik Indonesia Nomor 20 Tahun 2003 tentang Sisdiknas \& Peraturan Pemerintah R.I Tahun 2010 tentang Penyelenggeraan 